\title{
Cardiac autoimmunity in HIV related heart muscle disease
}

P F Currie, J H Goldman, A L P Caforio, A J Jacob, M K Baig, R P Brettle, A J Haven, N A Boon, W J McKenna

\begin{abstract}
Objective-To assess the frequency of circulating cardiac specific autoantibodies in HIV positive patients with and without echocardiographic evidence of left ventricular dysfunction.

Subjects-74 HIV positive patients including 28 with echocardiographic evidence of heart muscle disease, 52 HIV negative people at low risk of HIV infection, and 14 HIV negative drug users who had all undergone non-invasive cardiac assessment were studied along with a group of 200 healthy blood donors.
\end{abstract}

Results-Cardiac autoantibodies detected by indirect immunofluorescence (serum dilution 1/10) were more common in the HIV positive patients (15\%), particularly the HIV heart muscle disease group $(21 \%)$, than in HIV negative controls $(3.5 \%)$ (both $p<0.001$ ). By ELISA (dilution 1/320), abnormal anti- $\alpha$ myosin autoantibody concentrations were found more often in HIV patients with heart muscle disease $(43 \%)$ than in HIV positive patients with normal hearts $(19 \%)$ or in HIV negative controls $(3 \%)(p<0.05$ and $p<0.001$, respectively). Anti-a myosin autoantibody concentrations were greater in HIV positive patients than in HIV negative controls, regardless of cardiac status ((mean SD) $0.253(0.155) v$ $0.170(0.076) ; p=0.003)$. In particular the mean antibody concentration was higher in the HIV heart muscle disease patients $(0.291(0.160) \quad v 0.170 \quad(0.076) ; p=0.001)$ than in HIV negative controls. On follow up, six subjects with normal echocardiograms but raised autoantibody concentrations had died after a median of 298 days, three with left ventricular abnormalities at necropsy. This compared with a median survival of 536 days for 21 HIV positive patients with normal cardiological and immunological results.

Conclusions-There is an increased frequency of circulating cardiac specific autoantibodies in HIV positive individuals, particularly those with heart muscle disease. The data support a role for cardiac autoimmunity in the pathogenesis of HIV related heart muscle disease, and suggest that cardiac autoantibodies may be markers of the development of left ventricular dysfunction in HIV positive patients with normal hearts.

(Heart 1998;79:599-604)

Keywords: autoimmunity; autoantibodies; HIV infection; dilated cardiomyopathy
HIV related heart muscle disease can present as isolated left ventricular dysfunction or as a dilated cardiomyopathy. ${ }^{1}$ Cross sectional and prospective echocardiographic studies suggest that the prevalence of heart muscle disease in HIV positive patients is about $15 \%,{ }^{2-8}$ and it has recently been confirmed that both forms of this cardiac condition are a significant cause of morbidity and mortality in AIDS. ${ }^{910}$ The prevalence of HIV related heart muscle disease is likely to increase because more patients with HIV infection are surviving potentially fatal opportunistic infections associated with the development of AIDS, only to succumb to neoplasia or end organ damage such as heart disease or dementia. ${ }^{11}$

The aetiology of myocardial involvement in HIV infection is complex and remains obscure. However, autoimmune processes have been described in AIDS patients, ${ }^{12}$ and the discovery of a number of antibodies against cells other than $\mathrm{T}$ lymphocytes, ${ }^{14}$ along with the finding of increased myocardial expression of HLA class I antigen in AIDS patients with heart failure, ${ }^{15}$ suggests that cardiac autoimmunity could play a role in the pathogenesis of heart muscle disease in a subset of HIV positive patients.

Organ and disease specific anti-heart antibodies were first detected by indirect immunofluorescence in $30 \%$ of HIV negative patients with idiopathic dilated cardiomyopathy and in $20 \%$ of their symptom-free relatives. ${ }^{16}{ }^{17}$ Antigens recognised by these antibodies include cardiac $\alpha$ myosin. ${ }^{18-20}$ The occurrence of high titre organ and disease specific antibodies to $\alpha$ myosin in idiopathic dilated cardiomyopathy has been more recently confirmed by enzyme linked immunosorbent assay (ELISA). ${ }^{21}$ The importance of $\alpha$ myosin in cardiac autoimmunity has been further emphasised by experimental models, which have shown that susceptible mice develop cardiomyopathy with circulating organ specific antimyosin antibodies after exposure to coxsackievirus B3 infection $^{22}$ or immunisation with $\alpha$ myosin. $^{23}$ However, the prevalence of cardiac specific autoantibodies has not been reported in the context of HIV related heart muscle disease.

Our aim in this study was to assess the frequency and clinical significance of cardiac specific autoantibodies detected by immunofluorescence and ELISA in a population of HIV positive patients with and without heart muscle disease. All subjects had given informed consent and the study had the approval of the local ethics committee. 
Methods

PATIENTS

Serum was obtained from 28 HIV positive patients, mean (SD) age 34 (8) years (26 male, two female), who had been identified as having echocardiographic evidence of heart muscle disease in the course of a formerly reported, four year, prospective echocardiographic survey. ${ }^{9}$ Twelve had dilated cardiomyopathy and 16 had left ventricular dysfunction. Serum was also collected from a further nine HIV positive patients with isolated right ventricular dilatation, age 33 (11) years (eight male, one female). A control group of $37 \mathrm{HIV}$ positive patients from the same survey with no echocardiographic abnormalities was also studied (age 33 (5) years; 35 male, two female).

A diagnosis of AIDS according to the Centers for Disease Control and Prevention classification ${ }^{24}$ had been made in 44 of the HIV positive patients; 19 were suffering from advanced disease but with no AIDS defining illness, and a further seven were classified as group III. A contemporary classification was not available in four patients. Fifty four were injecting drug users, 16 were homosexual or bisexual men, one was a blood product recipient, and two had contracted the disease through heterosexual contact. The risk factor for a single patient was unknown.

Blood samples were obtained within 14 days of the index echocardiogram - that is, the study first confirming clinical normality or demonstrating cardiac dysfunction. The majority $(71 \%)$ of samples were obtained the same day. The mean CD 4 count at the time of the index echocardiogram was 68 cells $/ \mathrm{mm}^{3}$ (range 0-783 cells $/ \mathrm{mm}^{3}$ (normal 500-1500 cells $\left./ \mathrm{mm}^{3}\right)$ ). There was no significant difference in the age, sex, risk factors for HIV infection, CD4 counts, clinical condition, or time between blood sampling and index echocardiogram in the HIV positive groups. Patients receiving treatment with anthracycline drugs were excluded from the study, nor was there an excess of exposure to zidovudine in patients with heart muscle disease. Cocaine use was not reported in either of the injection drug user groups.

Symptoms and clinical signs of heart failure were common in patients with dilated cardiomyopathy $(8 / 12,66 \%)$, but were less frequent in those with left ventricular dysfunction $(5 / 16$, $31 \%$ ). Breathlessness was common in the patients with isolated right ventricular dilatation but was often attributable to pulmonary causes.

The HIV negative control group consisted of 52 HIV negative people (age 45 (16) years; 31 male, 21 female) who were at low risk of HIV infection, and a further comparative group of 14 HIV negative injection drug users (age 34.5 (9) years; 10 male, four female) attending a local drug rehabilitation unit. None of these subjects had evidence of heart disease after standard clinical and echocardiographic assessment. The normal control population for the immunofluorescence test was a group of 200 healthy blood donors (age 35 (11) years; 91 male, 109 female) who had been recruited previously. ${ }^{16}$
ECHOCARDIOGRAPHY

Phantom calibrated Hewlett Packard Sonos 100 and 1000 ultrasound machines with 2.5 and $3.5 \mathrm{MHz}$ transducers were used (Hewlett Packard, Camas, Washington, USA). Left ventricular $\mathrm{M}$ mode tracings were obtained from long and short axis parasternal views at the level of the mitral valve papillary muscles and on-screen calipers were used to measure end diastolic and systolic dimensions. Left ventricular fractional shortening was calculated as the difference between these measurements divided by the end diastolic size. The echocardiograms were stored on videotape and were later analysed by the operator and two independent blinded observers. The definitions for dilated cardiomyopathy, left ventricular dysfunction, and isolated right ventricular dilatation in these patients have been published previously, ${ }^{69}$ and are described below.

Dilated cardiomyopathy - A fractional shortening of $<28 \%$ with global left ventricular hypokinesia reported by all three observers.

Isolated right ventricular dysfunction - Right ventricular size greater than the left ventricle on standard cross sectional dimensional views.

Borderline left ventricular dysfunction-Left ventricular end systolic diameter $>55 \mathrm{~mm}$ but preserved systolic function (fractional shortening $>28 \%$ ) or global left ventricular dysfunction reported by one or two but not all three observers.

CD4 counts from the HIV positive group were obtained by lymphocyte immunophenotyping using a Becton Dickinson FACScan TM flowcytometer (Becton Dickinson, Oxford, $\mathrm{UK})$.

IMMUNOFLUORESCENCE ASSAY FOR ANTI-HEART ANTIBODY

Serum samples were tested by standard indirect immunofluorescence at $1 / 10$ dilution on $4 \mu \mathrm{m}$ thick unfixed fresh frozen cryostat sections of blood group $\mathrm{O}$ normal human atrium and skeletal muscle, as described previously. ${ }^{16}{ }^{17}$ The antibody titres were measured by doubling dilutions of sera in phosphate buffered solution and the antibody patterns were classified as negative, weak, or strongly positive by a single observer (ALPC) who was blinded to the clinical information. "Organ specific" antibodies produced a diffuse cytoplasmic staining of myocytes, while "cross reactive type 1 " antibodies produced a fine striational immunofluorescence on the cardiac tissue, but would only stain skeletal muscle weakly. ${ }^{16}$ Two sera were used as standard positive (antibody titre $>1 / 40$ ) and negative controls and titrated in every assay. The normal control population was assessed by the same observer and $3.5 \%$ were found to be positive for organ specific cardiac autoantibodies. ${ }^{16}$

ELISA

The development and methodology of this $\alpha$ myosin specific ELISA have been described previously. ${ }^{21}$ Serum samples from patients and controls were analysed by two operators (JHG and $\mathrm{MKB}$ ) who were, for reasons of safety, aware of the HIV status but were otherwise 
Table 1 Frequency of anti-heart autoantibodies in HIV positive and negative patients by immunofluorescence

\begin{tabular}{lll}
\hline & $\begin{array}{l}\text { Cardiac } \\
\text { specific (\%) }\end{array}$ & $\begin{array}{l}\text { Cardiac cross } \\
\text { reactive (\%) }\end{array}$ \\
\hline All HIV+ve (n = 74) & $11(15)^{\star}$ & 0 \\
HIV+ve normal heart $(\mathrm{n}=37)$ & $4(11)$ & 0 \\
HIV+ve HMD ( $=28)$ & $6(21)^{\star}$ & 0 \\
HIV+ve RVD $(\mathrm{n}=9)$ & $1(11)$ & 0 \\
HIV-ve IDUs $(\mathrm{n}=14)$ & 0 & $2(14)$ \\
HIV-ve NBDs $(\mathrm{n}=200)$ & $7(3.5)$ & $11(5.5)$
\end{tabular}

${ }^{{ } \mathrm{p}}<0.001 v$ NBD by $\chi^{2} ;$ no other significant difference between groups by $\chi^{2}$.

HMD, heart muscle disease; IDUs, injection drug users; NBDs, normal blood donors; RVD, isolated right ventricular dilatation; +ve, positive; -ve, negative.

blinded to the clinical status of each subject. Ninety six well enzyme linked immunosorbent assay plates (Immulon 1; Dynatech, W Sussex, UK) were coated with sequential duplicates of $100 \mu \mathrm{l}$ purified human atrial myosin at a concentration of $5 \mu \mathrm{g} / \mathrm{ml}$. Control wells contained buffer alone. Plates were incubated for one hour at $37^{\circ} \mathrm{C}$ with shaking and washed six times with phosphate buffered saline (PBS) solution (Sigma, Poole, UK) containing $0.1 \%$ Tween 20 (PBS-T). All wash steps between incubations were identical. Wells were blocked with $200 \mu \mathrm{l}$ PBS-T containing $2 \%$ bovine serum albumin fraction V (Sigma), then incubated for half an hour at $37^{\circ} \mathrm{C}$ with shaking, and washed. Wells were next coated with $100 \mu$ duplicates of each serum sample. These were diluted at 1/320 in PBS-T containing $1 \%$ phosphate buffered saline, and had previously been centrifuged at $16800 \times g$ for two minutes. Each plate in each assay contained a positive control serum sample from the same HIV negative patient with idiopathic dilated cardiomyopathy, who showed consistently high responses. The layout of each plate included four blank wells that contained medium alone. Plates were incubated for one hour at $37^{\circ} \mathrm{C}$ with shaking and then washed. Wells were then coated with $100 \mathrm{ml}$ of biotinylated goat antihuman IgG $\gamma$ chain (Vector Laboratories, Peterborough, UK) diluted $1 / 1000$ in PBS-T, incubated for one hour at $37^{\circ} \mathrm{C}$ with shaking, and washed. Avidinperoxidase complex solution (Vector Laboratories) was prepared according to the manufacturer's instructions by dilution in PBS-T one hour before use, and stored at $4^{\circ} \mathrm{C}$. One hundred microlitres of avidin-peroxidase complex were added to each well, and plates were incubated for one hour at $37^{\circ} \mathrm{C}$ with shaking, and washed. Finally, plates were coated with $100 \mu \mathrm{l}$ of orthophenyl diamene substrate (Sigma) and incubated for 15 minutes at $37^{\circ} \mathrm{C}$ in the dark without agitation; absorbence was

Table 2 Results of anti-a myosin antibody by ELISA (absorbence at $450 \mathrm{~nm}$ )

\begin{tabular}{lll}
\hline Group & Mean $(S D)$ & $\begin{array}{l}\text { Frequency of abnormal } \\
\text { results }(\%)\end{array}$ \\
\hline All HIV positive $(\mathrm{n}=74)$ & $0.253(0.155)$ & $21(28) \star$ \\
All HIV negative $(\mathrm{n}=66)$ & $0.170(0.076)$ & $2(3)$ \\
HIV positive HMD $(\mathrm{n}=28)$ & $0.291(0.160)$ & $12(43) \dagger \ddagger$ \\
HIV positive normal heart $(\mathrm{n}=37)$ & $0.227(0.157)$ & $7(19)$ \\
HIV negative drug users $(\mathrm{n}=14)$ & $0.136(0.086)$ & $1(7)$ \\
HIV negative non-drug users $(\mathrm{n}=52)$ & $0.179(0.071)$ & $1(2)$ \\
\hline
\end{tabular}

${ }^{\star} \mathrm{p}<0.001 v$ all HIV negative controls; $\nmid \mathrm{p}<0.05 v$ HIV positive normal heart; $\neq \mathrm{p}<0.001 v$ all HIV negative controls.

HMD, heart muscle disease. assessed immediately using a Pasteur Diagnostics ELISA reader at $450 \mathrm{~nm}$, linked to Arcom Macintosh software. The upper limit of normal for the ELISA for antibodies to $\alpha$ myosin absorption was 0.32 (mean +2 SD of the HIV negative non-drug user group).

\section{STATISTICS}

The mean ELISA antibody concentrations, echocardiographic indices, and CD4 counts for each patient group were calculated and compared by analysis of variance and the Mann-Whitney U tests using a Systats statistical program running on an IBM compatible PC. The frequency of abnormal ELISA and immunofluorescence results in each group was compared by the $\chi^{2}$. A probability ( $\mathrm{p}$ ) value of $<0.05$ was taken as significant.

\section{Results}

IMMUNOLOGICAL FINDINGS

Cardiac specific autoantibodies detected by indirect immunofluorescence were more common in the HIV positive patient population $(15 \%)$, and in the HIV related heart muscle disease group in particular $(21 \%)$, than in HIV negative healthy normal controls from a previous study $(3.5 \%)^{16}$ (both $\left.\mathrm{p}<0.001\right)$ (table 1 ). There was no significant difference in the frequency of these antibodies in the HIV positive patients with no echocardiographic abnormality $(11 \%)$, or in those patients with isolated right ventricular dilatation ( $11 \%$ ) compared with healthy blood donors. Two HIV negative intravenous drug users (14\%) were weakly positive for cross reactive anti-heart antibodies, but this was not significantly different from the incidence of these antibodies in the normal control group (5.5\%).

The mean anti- $\alpha$ myosin antibody concentrations by ELISA are shown in table 2 . Values were higher in HIV positive patients than in the HIV negative control group (mean (SD) absorbence, 0.253 (0.155) $v 0.170$ (0.076); $\mathrm{p}=0.003)$. The mean anti- $\alpha$ myosin antibody titre was significantly higher in HIV patients with heart muscle disease than in the HIV negative control group (0.291 (0.160) $v 0.170$ $(0.076) ; p=0.001)$, and the heart muscle disease group tended to have higher antibody concentrations than the HIV positive controls with no echocardiographic abnormality $(0.291$ (0.160) $v 0.227$ (0.157); $\mathrm{p}=0.07)$.

The incidence of abnormally raised anti- $\alpha$ myosin antibodies was significantly higher in the whole HIV positive group (28\%) than in the HIV negative controls $(3 \% ; \mathrm{p}<0.001)$ (fig 1). In particular raised antibody levels were more common in the patients with heart muscle disease (43\%) compared to HIV positive normal heart $(19 \%$; $<0.05)$ and HIV negative controls $(3 \% ; \mathrm{p}<0.001)$. There was no significant difference between mean level or prevalence of anti- $\alpha$ myosin antibody in the HIV positive individuals with normal hearts and those with right ventricular dilatation, or between the HIV negative drug users and nondrug users. There was no correlation between either the ELISA or immunofluorescence results 


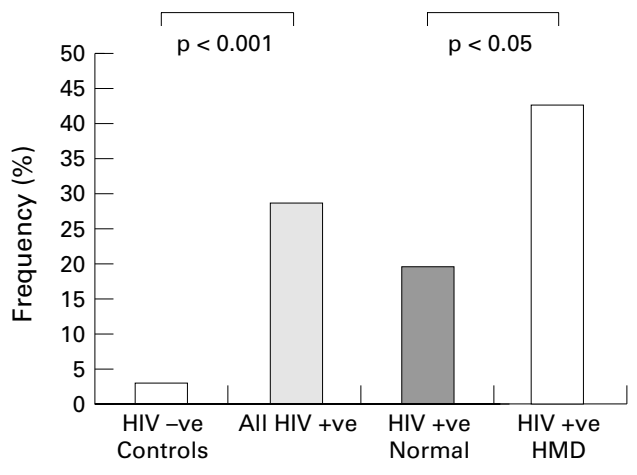

Figure 1 Frequency of anti-a myosin antibody by ELISA (absorbence at $450 \mathrm{~nm}$ ). -ve, negative; +ve, positive; $H M D$, heart muscle disease.

and age, sex ratio, echocardiographic measurements, or CD4 count (data not shown).

Nine patients had abnormal autoantibody results despite normal echocardiograms. Of these, three had abnormal ELISA results with positive immunofluorescence, four had only abnormal ELISA, and two had positive immunofluorescence alone.

CLINICAL FEATURES AT FOLLOW UP

All of the 74 HIV positive patients were followed routinely at a specialist clinic, where complete detailed clinical and immunological records had been kept. Their clinical status was reviewed from the case notes after a mean period of 4.3 years (range 1.6 to 6.8 years) from the time of the echocardiographic diagnosis. Eighteen of the cohort had survived (median (range) survival time 319 days (5 to 2374)), including four with heart muscle disease in the form of left ventricular dysfunction (171 days (5 to 1296)) and two with right ventricular dysfunction (382 days (48 to 1237)).

Six of the nine patients with structurally normal hearts but abnormal autoantibody results had died. Chest $x$ rays performed before death had shown no evidence of cardiomegaly or heart failure in these cases, but three necropsy examinations had shown left ventricular abnormalities including left ventricular dilatation with pulmonary oedema, myocyte atrophy, or a focal inflammatory infiltrate. Three of these nine patients survived. Two had been lost to regular follow up but were known to be alive, and the third declined further echocardiographic study.

The median survival from the time of the index echocardiogram for the patients with abnormal autoantibody results despite structurally normal hearts was 298 days (range 98 to 898 ) compared to a median of 536 days ( 80 to 2374) for the 21 patients with both normal echocardiogram and cardiac autoantibody results who had died. There was no significant difference in the CD4 counts or clinical status of these groups.

\section{Discussion}

The aetiology of HIV related heart muscle disease remains obscure although there does appear to be a loose association between heart failure and cardiac dysfunction and cases of lymphocytic myocarditis reported in some AIDS necropsy series. ${ }^{25-29}$ However, it should be noted that routine histological methods may be of limited value in the setting of severe immunosuppression, and that recent immunohistological studies have suggested that active myocarditis is more common in AIDS patients with cardiac dysfunction than previously realised. ${ }^{15}$

Overall, HIV related heart muscle disease is characterised by left ventricular dysfunction similar to idiopathic dilated cardiomyopathy in HIV negative individuals. Although abnormalities of the right ventricle have also been a frequent finding in HIV positive patients, ${ }^{5} 6$ 30-32 isolated right ventricular dysfunction is not associated with a poor prognosis ${ }^{9}$ and is most probably related to pulmonary arterial disease or recurrent bronchopulmonary infections ${ }^{33}$ rather than to primary myocardial disease.

In this study we detected an increased frequency of circulating cardiac specific autoantibodies in HIV positive individuals, particularly those with documented myocardial involvement, ranging from overt dilated cardiomyopathy to asymptomatic left ventricular dysfunction. These antibodies, determined using two standardised techniques, have been found to be disease specific for a subset $30 \%$ to $40 \%$ ) of HIV negative patients with idiopathic dilated cardiomyopathy and a proportion of their symptom-free relatives, and represent markers of autoimmunity in this condition. ${ }^{16} 1721$ Additional autoimmune features present in idiopathic cardiomyopathy include familial aggregation of disease, ${ }^{34-36}$ the HLA-DR4 haplotype, ${ }^{37-39}$ inappropriate expression of HLA class II antigen on cardiac endocardium/ endothelium, ${ }^{40}$ and abnormalities of cellular immunity. ${ }^{41} 42$

This study has some limitations in that longitudinal serological assessments were not made and the numbers of both HIV positive patients and controls are small. In particular, HIV negative drug users were difficult to identify, as many otherwise suitable candidates had either refused previous HIV testing or proved unreliable clinic attenders. Despite this, the finding of cardiac specific antibodies presented here is strongly suggestive of autoimmune involvement in the pathogenesis of HIV related heart muscle disease. Moreover, these antibodies are not found in HIV negative drug users, suggesting that they are not related to lifestyle and are more likely to be a sequel of HIV infection itself. This is in keeping with reports of other autoimmune disorders in HIV infection, including idiopathic thrombocytopenic purpura, ${ }^{12}{ }^{13}$ Sjögren's syndrome, ${ }^{43}$ and bullous skin disease. ${ }^{44}$ In addition, increased concentrations of circulating immune complexes and various non-organ specific autoantibodies are well described in HIV positive patients. ${ }^{14} 45$

Autoantibodies against the adenosine nucleotide translocator, a mitochondrial antigen, and $\beta$ myosin (which is cross reactive with skeletal muscle) have been found in a small group of HIV positive patients with active myocarditis. ${ }^{46}$ However, the occurrence of the 
cardiac specific autoantibodies detected by immunofluorescence and by anti- $\alpha$ myosin ELISA has not previously been reported in the context of HIV infection.

There may be a role for common viruses in causing or facilitating the onset of cardiac autoimmunity in HIV positive patients. For example, it has been suggested that cardiotropic viruses could modify existing surface antigens or expose other hidden epitopes on the cell surface, leading to an aberrant autoimmune response against endogenous autoantigenic peptides associated with the HLA molecules. ${ }^{47}$ Experimental evidence for these theories has been found in studies on cytomegalovirus and coxsackievirus B3 myocarditis in mice. ${ }^{48} 49$

HLA class I antigens are not normally expressed by myocytes under normal conditions or in idiopathic dilated cardiomyopathy ${ }^{40}$ but, using immunoperoxidase methods, sarcolemmal staining has been reported in HIV negative patients with myocarditis. ${ }^{47} \mathrm{~A}$ specific CD8 lymphocyte response targeting myocytes that are expressing viral peptides in association with HLA class I antigens has also been demonstrated in HIV positive patients. ${ }^{15}$

Cytomegalovirus infection is one of the most common opportunistic infections in AIDS patients. Despite this, it has been described only infrequently as a cause of myocarditis in HIV patients, ${ }^{50-52}$ and always on the background of disseminated infection. Although our previous work has suggested that neither cytomegalovirus nor toxoplasma is implicated in the pathogenesis of HIV related heart muscle disease, ${ }^{6}$ recent in situ hybridisation studies have identified transcripts of DNA specific to the cytomegalovirus genome within the myocytes of HIV positive patients with myocarditis and cardiomyopathy, in whom typical histological features such as inclusion bodies were not found. ${ }^{15} 5053$ Cytomegalovirus, or some other hitherto unidentified factor, may yet prove to be the trigger for an autoimmune reaction. Alternatively, as recently suggested, HIV itself could induce immune dysregulation in patients who are predisposed to autoimmune disease by HLA or non-HLA genes. $^{54-56}$

It is not possible to assess whether the presence of cardiac specific autoantibodies is independently predictive of outcome or long term prognosis. However, the nine HIV positive patients with structurally normal hearts and abnormal autoantibody results did appear to have a shorter median survival than those with both normal echocardiogram and serological results. While it is possible that this represents false positivity for our assays, there were also findings suggestive of cardiac involvement in three of the subjects who underwent necropsy examination.

Our finding of increased cardiac specific autoantibodies in HIV positive patients with evidence of heart muscle disease suggests that cardiac autoimmunity may be an important factor in the development of left ventricular dysfunction in AIDS patients. Anti-heart antibodies associated with myocarditis ${ }^{57}$ and di- lated cardiomyopathy ${ }^{16}$ have been described in HIV negative individuals and may also provide a serological marker of cardiac autoimmunity and ongoing myocardial injury in AIDS patients in the future.

We thank Dr Sheila Burns (Regional Virus Laboratory, Edinburgh) for help with sample collection, Professor Michael J Davies (St George's Hospital, London) for providing laboratory space and equipment, and $\mathrm{Mr} \mathrm{R}$ Warraich for technical assistance. Dr Peter F Currie, Dr Jonathan H Goldman, and Dr Aldwyn J Haven are supported by the British Heart Foundation. Dr Alida L P Caforio is supported by the Veneto Region Target Project on Cardiomyopathies (Venice, Italy) and by the National Research Council target project "FAT.MA" (Rome, Italy). We also acknowledge the expert secretarial assistance of Mrs Jean Cunningham.

1 Cohen IS, Anderson DW, Virmani R, et al. Congestive cardiomyopathy in association with the acquired immunodeficiency syndrome. $N$ Engl f Med 1986;315:628-30.

2 Corallo S, Mutinelli MR, Moroni M, et al. Echocardiography detects myocardial damage in AIDS: prospective study in 102 patients. Eur Heart $\mathcal{F}$ 1988;9:887-92.

3 Himelman B, Chung WS, Chernoff DN, et al. Cardiac manifestations of human immunodeficiency virus infection: a two-dimensional echocardiographic study. $\mathcal{F}$ Am Coll Cardiol 1989;13:1030-6.

4 Lipshultz SE, Chanock S, Sanders SP, et al. Cardiovascular manifestations of human immunodeficiency virus infection in infants and children. Am f Cardiol 1989;63:1489-97.

5 Blanchard DG, Hagenhoff C, Chow LC, et al. Reversibility of cardiac abnormalities in human immunodeficiency virus (HIV)-infected individuals; a serial echocardiographic study. F Am Coll Cardiol 1991;17:1270-6.

6 Jacob AJ, Sutherland GR, Bird AG, et al. Myocardial dysfunction in patients infected with HIV: prevalence and risk factors. Br Heart $\mathcal{F} 1992 ; 68: 549-5$.

7 Herskowitz A, Vlahov D, Willoughby S, et al. Prevalence and incidence of left ventricular dysfunction in patients with human immunodeficiency virus infection. Am 7 Cardiol 1993;71:955-8.

8 De Castro S, Migliau G, Silvestri A, et al. Heart involvement in AIDS: a prospective study during various stages of the disease. Eur Heart f 1992;13:1452-9.

9 Currie PF, Jacob AJ, Foreman AR, et al. Heart muscle disease related to HIV infection: prognostic implications. disease related to HIV

10 De Castro S, D'Amati G, Gallo P, et al. Frequency of development of acute global left ventricular dysfunction in human immunodeficiency virus infection. f Am Coll Cardiol 1994;24:1018-24.

1 Peters BS, Beck EJ, Coleman DG, et al. Changing disease patterns in patients with AIDS in a referral centre in the United Kingdom: the changing face of AIDS. BMF 1991;302:203-7.

12 Sloand EM, Klein HG, Banks SM, et al. Epidemiology of thrombocytopenia in HIV infection. Eur f Haematol 1992; 48:168-72.

13 Bettaieb A, Fromont P, Louache F, et al. Presence of crossreactive antibody between human immunodeficiency virus (HIV) and platelet glycoproteins in HIV-related immune thrombocytopenic purpura. Blood 1992;80:162-9.

14 Klaassen RJLK, Vlekke ABJ, von dem Borne AEGK. Neutrophil-bound immunoglobulin in HIV infection is of autoantibody nature. Br f Haematol 1991;77:403-9.

15 Herskowitz A, Wu TC, Willoughby S, et al. Myocarditis and cardiotropic viral infection associated with severe left ventricular dysfunction in late stage infection with human immunodeficiency virus. F Am Coll Cardiol 1994;24:102532 .

16 Caforio ALP, Bonifacio E, Stewart JT, et al. Novel organ-specific cardiac autoantibodies in dilated cardiomyopathy. F Am Coll Cardiol 1990;15:1527-34.

17 Caforio ALP, Keeling PJ, Zachara E, et al. Evidence from family studies for autoimmunity in dilated cardiomyopathy. Lancet 1994;344:773-7.

18 Bouvagnet $\mathrm{P}$, Mairhofer $\mathrm{H}$, Leger JO, et al. Distribution pattern of alpha and beta myosin in normal and diseased tern of alpha and beta myosin in normal and diseased human venti

19 Caforio ALP, Grazzini M, Mann JM, et al. Identification of the $\alpha$ and $\beta$ myosin heavy chain isoforms as major autoantigens in dilated cardiomyopathy. Circulation 1992;85: $1734-42$.

20 Latif N, Baker CS, Dunn MJ, et al. Frequency and specificity of antiheart antibodies in patients with dilated cardiomyopathy detected using SDS-PAGE and western blotting. F Am Coll Cardiol 1993;22:1378-84.

21 Goldman JH, Keeling PJ, Baig MK, et al. Autoimmunity to $\alpha$ myosin in a subset of patients with idiopathic dilated cardiomyopathy. Br Heart f 1995;74:598-603.

22 Neu N, Beisel KW, Traystmann MD, et al. Autoantibodies specific for the cardiac myosin isoform are found in mice specific for the cardiac myosin isoform are found in mice
susceptible to coxsackievirus B3-induced myocarditis. $\mathfrak{F}$ Immunol 1987;138:2488-92.

23 Neu N, Rose NR, Beisel KW, et al. Cardiac myosin induces myocarditis in genetically predisposed mice. F Immunol 1987;139:3630-6. 
24 Centers for Disease Control. Current trends: classification system for human $\mathrm{T}$ lymphotropic virus type III/ lymphadenopathy

25 Anderson DW, Virmani R, Reilly JM, et al. Prevalent myocarditis at necropsy in the acquired immunodeficiency syndrome. 7 Am Coll Cardiol 1988;11:792-9.

26 Baroldi G, Corallo S, Moroni M, et al. Focal lymphocytic myocarditis in acquired immunodeficiency syndrome (AIDS); a correlative morphologic and clinical study in 26 consecutive fatal cases. F Am Coll Cardiol 1988;12:463-9.

27 Reilly JM, Cunnion RE, Anderson DW, et al. Frequency of myocarditis, left ventricular dysfunction and ventricular tachycardia in the acquired immune deficiency syndrome. Am f Cardiol 1988;62:789-93.

28 Anderson DW, Virmani R. Emerging patterns of heart disease in human immunodeficiency virus infection. Hum Pathol 1990;21:253-9.

29 Lewis W, Grody WN. AIDS and the heart: review and consideration of pathogenic mechanisms. Cardiovasc Pathol 1992;1:53-64.

30 Himelman RB, Dohrmann M, Goodman P, et al. Severe pulmonary hypertension and cor pulmonale in the acquired immunodeficiency syndrome. Am f Cardiol 1989; 64:1396-9

31 Lewis W. AIDS: cardiac findings from 115 autopsies. Prog Cardiovasc Dis 1989;32:207-15.

32 Raffanti SR, Chiaramida AJ, Sen P, et al. Assessment of cardiac function in patients with the acquired immunodeficiency syndrome. Chest 1988;93:592-4.

33 Coplan NL, Shimony RY, Ioachim HL, et al. Primary pulmonary hypertension associated with human immunodeficiency viral infection. Am $\mathcal{F}$ Med 1990;89:906-9.

34 Michels VV, Moll PP, Miller FA, et al. The frequency of familial dilated cardiomyopathy in a series of patients with idiopathic dilated cardiomyopathy. N Engl f Med 1992;326: 1diopathic

35 Zachara E, Caforio AL, Carboni GP, et al. Familial aggregation of idiopathic dilated cardiomyopathy: clinical features tion of idiopathic dilated cardiomyopathy: clinical features and pediger.

36 Keeling PJ, Gang Y, Seo H, et al. Familial dilated cardiomyopathy in the United Kingdom. Br Heart $\mathcal{F}$ 1995;73:41721.

37 Anderson JL, Carlquist JF, Lutz JR, et al. HLA A, B and DR typing in idiopathic dilated cardiomyopathy: a search fo immune response factors. Am f Cardiol 1984;53:1326-30

38 Carlquist JF, Menlove RL, Murray MB, et al. HLA class II (DR and DQ) antigen associations in idiopathic dilated cardiomyopathy. Validation study and meta-analysis of published HLA association studies. Circulation 1991;83: 515-22.

39 Martinetti M, Dugoujon JM, Caforio AL, et al. HLA and immunoglobulin polymorphisms in idiopathic dilated cardiomyopathy. Hum Immunol 1992;35:193-9.

40 Caforio AL, Stewart JT, Bonifacio E, et al. Inappropriate major histocompatibility complex expression on cardiac tissue in dilated cardiomyopathy. Relevance for autoimmunity? f Autoimmunity 1990;3:187-200.
41 Limas CJ, Goldenberg IF, Limas C. Soluble interleukin-2 receptor levels in patients with dilated cardiomyopathy. Correlation with disease severity and cardiac autoantibodies. Circulation 1995;91:631-4.

42 Marriott JB, Goldman JH, Keeling PJ, et al. Abnormal cytokine profiles in patients with idiopathic dilated cardiomyopathy and their asymptomatic relatives. Br Heart $\mathcal{f}$ 1996;75: 287-90.

43 Procaccia S, Blasio R, Villa P, et al. Rheumatoid factors and circulating immune complexes in HIV-infected individuals. AIDS 1991;5:1441-6.

44 Chou K, Kauh YC, Jacoby RA, et al. Autoimmune bullous disease in a patient with HIV infection. 7 Am Acad Dermatol 1992;24:1022-3.

45 Golding H, Robey FA, Gates FT, et al. Identification of homologous regions in human immunodeficiency virus I gp 41 and human MHC class II beta 1 domain. I. Monoclonal antibodies against the gp 41-derived peptide and patients' sera react with native HLA class II antigens, suggesting a role for autoimmunity in the pathogenesis of acquired immune deficiency syndrome. f Exp Med 1988;167:914-23.

46 Herskowitz A, Ansari AA, Neumann DA, et al. Cardiomyopathy in acquired immunodeficiency syndrome: evidence for autoimmunity. Circulation 1989;80:322.

47 Herskowitz A, Ahmed-Ansari A. Myocarditis. Curr Opin Cardiol 1992; 7:469-75.

48 Price P, Eddy KS, Papadimitriou JM, et al. Genetic determination of cytomegalovirus-induced and age-related cardiomyopathy in inbred mice. Characterization of infiltrating cells. Am f Pathol 1991;138:59-67.

49 Lodge PA, Herzum M, Olszewski J, et al. Coxsackievirus B-3 myocarditis. Acute and chronic forms of the disease caused by different immunopathogenic mechanisms. Am 7 Pathol 1987;128:455-63.

50 Neidt GW, Schinella RA. Acquired immunodeficiency syndrome: clinico-pathological study of 56 autopsies. Arch Pathol Lab Med 1987;111:943-6.

51 Monsuez J, Kinney EL, Vittecoq D, et al. Comparison among acquired immune deficiency syndrome patients Cardiol 1988;62:1311-13.

52 Wu T-C, Pizzorno MC, Hayward GS, et al. In situ detection of human cytomegalovirus immediate-early gene transcripts within cardiac monocytes of patients with HIVassociated cardiomyopathy. AIDS 1992,6.777-85.

53 Meyerson D, Hackman RC, Nelson JA, et al. Widespread presence of histologically occult cytomegalovirus. Hum Pathol 1984;15:430-9.

54 Via CS, Morse, HC, Shearer GM. Altered immunoregulation and autoimmune aspects of HIV infection: relevant murine models. Immunol Today 1990;11:250-5.

55 Mountz JD, Talal N. Retroviruses, apoptosis and autogenes. Immunol Today 1993;14:532-6.

56 Del Prete G, Maggi E, Pizzolo G, et al. CD 30, Th2 cytokines and HIV infection: a complex and fascinating link. Immunol Today 1995;16:76-80.

57 Lauer B, Padberg K, Schultheiss HP, et al. Autoantibodies against human ventricular myosin in sera of patients with acute and chronic myocarditis. 7 Am Coll Cardiol 1994;23: $146-53$. 